\title{
Two-dimensional electric field measurements in the ionospheric footprint of a flux transfer event
}

\author{
K. A. McWilliams, T. K. Yeoman, S. W. H. Cowley \\ Department of Physics and Astronomy, Leicester University, University Road, Leicester LE1 7RH, UK
}

Received: 17 May 2000 / Revised: 5 September 2000 / Accepted: 12 September 2000

\begin{abstract}
Line-of-sight Doppler velocities from the SuperDARN CUTLASS HF radar pair have been combined to produce the first two-dimensional vector measurements of the convection pattern throughout the ionospheric footprint of a flux transfer event (a pulsed ionospheric flow, or PIF). Very stable and moderate interplanetary magnetic field conditions, along with a preceding prolonged period of northward interplanetary magnetic field, allow a detailed study of the spatial and the temporal evolution of the ionospheric response to magnetic reconnection. The flux tube footprint is tracked for half an hour across six hours of local time in the auroral zone, from magnetic local noon to dusk. The motion of the footprint of the newly reconnected flux tube is compared with the ionospheric convection velocity. Two primary intervals in the PIF's evolution have been determined. For the first half of its lifetime in the radar field of view the phase speed of the PIF is highly variable and the mean speed is nearly twice the ionospheric convection speed. For the final half of its lifetime the phase velocity becomes much less variable and slows down to the ionospheric convection velocity. The evolution of the flux tube in the magnetosphere has been studied using magnetic field, magnetopause and magnetosheath models. The data are consistent with an interval of azimuthally propagating magnetopause reconnection, in a manner consonant with a peeling of magnetic flux from the magnetopause, followed by an interval of anti-sunward convection of reconnected flux tubes.
\end{abstract}

Key words: Magnetospheric physics (magnetosphereionosphere interactions; plasma convection; solar windmagnetosphere interactions)

Correspondence to: K. A. McWilliams

e-mail:k.mcwilliams@ion.le.ac.uk

\section{Introduction}

The nature of reconnection at the dayside magnetopause is fundamental to comprehending the primary means of energy input into the terrestrial magnetosphere. For more than 20 years spacecraft have been making measurements at the magnetopause in the vicinity of magnetic reconnection. Haerendel et al. (1978) published the first observations of episodes of reconnection at the magnetopause. The bipolar signature in the normal component of the magnetic field at the magnetopause is interpreted as that of a newly reconnected flux tube passing very near to the spacecraft and has been studied quite extensively (Haerendel et al., 1978; Russell and Elphic, 1978, 1979; Lockwood and Wild, 1993; Kuo et al., 1995). These bursts of reconnection have come to be known as flux transfer events, or FTEs.

Goertz et al. (1985) first suggested that measurements in the ionosphere might be useful in the study of magnetospheric reconnection. Goertz et al. (1985) used the STARE radar (Greenwald et al., 1978) to study antisunward flows poleward of the convection reversal boundary; they observed an occasional poleward flow component, and bursts of flow crossing the convection reversal boundary with scale sizes of 50 to $300 \mathrm{~km}$ and repetition rates of the order of minutes. These flows are the expected response to bursts of reconnection on the dayside magnetopause. The ionosphere has since been shown to respond to flux transfer events (Elphic et al., 1990; Moen et al., 1995; Yeoman et al., 1997; Neudegg et al., 1999).

Poleward moving patches of high velocity plasma seen in HF radar data have been suggested to be the ionospheric footprint of flux transfer events, supported by particle data from DMSP satellites (Pinnock et al., 1991, 1993). The unique comparison by Neudegg et al. (1999) presented simultaneous measurements of a bipolar magnetic field variation observed on board the Equator-S spacecraft at the magnetopause and a poleward moving ionospheric flow burst measured near the 
magnetically conjugate point in the ionosphere. McWilliams et al. (2000) showed statistically that there was very good agreement between the periodicities of flux transfer events observed in space (Lockwood and Wild, 1993; Kuo et al., 1995), optically observed poleward moving auroral forms (Fasel, 1995), and HF radar PIFs.

In the dayside auroral zone, there are several characteristics which affect the measured HF radar parameters. The strong backscattered power in the highvelocity PIF signature is typical of dayside cusp region scatter (Milan et al., 1998; Yeoman et al., 1997). Polar patches have been reported to have similar properties (Weber et al., 1984). High spectral widths, indicative in HF radar data of the ionospheric footprint of the magnetospheric cusp (Baker et al., 1995), can be used as an indicator of PIFs. Whilst wide spectra do indicate a spread of velocities, it is primarily indicative of turbulence in the sampling volume (Andre et al., 1999). The velocity fitted to a wider spectrum represents the bulk plasma drift in the measurement volume. The motion of the equatorward boundary of the high spectral width region in the ionosphere can be taken as a proxy of the motion of the ionospheric footprint of the magnetopause reconnection X-line (Milan et al., 1999).

Radar studies have relied mainly on monostatic measurements of PIFs. These studies have been limited by the lack of knowledge of the full vector ionospheric plasma convection velocity. The classic radar PIF signature, a spatially localised patch of high-velocity radar scatter moving anti-sunward, have been the subject of several case studies (Pinnock et al., 1995; Provan et al., 1998) and statistical surveys (Provan and Yeoman, 1999; McWilliams et al., 2000) based on measurements from a single radar. Chisham et al. (2000) studied data from three high-time resolution beams from two overlapping SuperDARN radars in the Southern Hemisphere. They examined the large-scale flows associated with PIF activity and their relationship to the changing orientation of the interplanetary magnetic field (IMF), focusing on convection velocities measured by the overlapping high-time resolution beams. Their measurements were obtained in the noon sector in the region of the initial ionospheric response to the flux transfer events. Chisham et al. (2000) were unable to determine the convection in the latter part of the PIF trajectory. Radar studies of PIFs have been limited even further in that they relied mainly on the high-time resolution data measured along a single radar beam. Provan et al. (1998) took advantage of a radar scan mode which had two high-time resolution beams to estimate the motion of the PIF across the radar field of view. The Fourier analysis method of McWilliams et al. (2000) showed that both the normal and the high-time resolution data were in excellent agreement. The substantial body of PIF radar research has demonstrated, therefore, that HF radars are an excellent tool for routine monitoring of dayside reconnection. Here we present bistatic measurements, with complete radar scans available at one-minute resolution, over the full extent of a PIF, allowing a detailed analysis of the PIF trajectory and of the convective flows within the feature.

\section{Experiment}

The data used in this study were obtained from the Cooperative UK Twin Located Auroral Sounding System (CUTLASS) (Milan et al., 1997), a pair of pulsed monostatic HF radars located at Hankasalmi, Finland $\left(62.32^{\circ} \mathrm{N} ; 26.61^{\circ} \mathrm{E}\right)$ and at Pykkibaer, Iceland $\left(63.86^{\circ} \mathrm{N}\right.$; $\left.19.20^{\circ} \mathrm{W}\right)$. The radars are a part of the international Super Dual Auroral Radar Network (SuperDARN) (Greenwald et al., 1995), which covers a vast portion of the northern and southern auroral zones and polar caps. Throughout this study, the radars will be referred to as "Finland" and "Iceland East". (There are two SuperDARN radars on Iceland and the CUTLASS Iceland radar is directed eastward.) The SuperDARN radars measure high-latitude plasma convection, or equivalently the electric field, in the Northern and Southern Hemispheres at E-region and F-region altitudes. The field-of-view of the CUTLASS radar pair at 11:00 UT is shown in Fig. 1 in geomagnetic co-ordinates. The radars cover nearly $6 \mathrm{~h}$ in magnetic local time at latitudes between $75^{\circ}$ and $80^{\circ}$, the region of interest for the current study. The arrow in Fig. 1 is the approximate trajectory of the feature of interest in the present study.

During the common mode of operation the SuperDARN radars step through a series of sixteen consecutive beam positions. The beam is produced by an array of sixteen log-periodic antennas and an electronically controlled phasing matrix, which steers the radar beam through its sequential sixteen-position scan. The data used in this study were measured during what is known as the "fast common mode" of operation. In fast common mode the dwell time along each beam is $3 \mathrm{~s}$

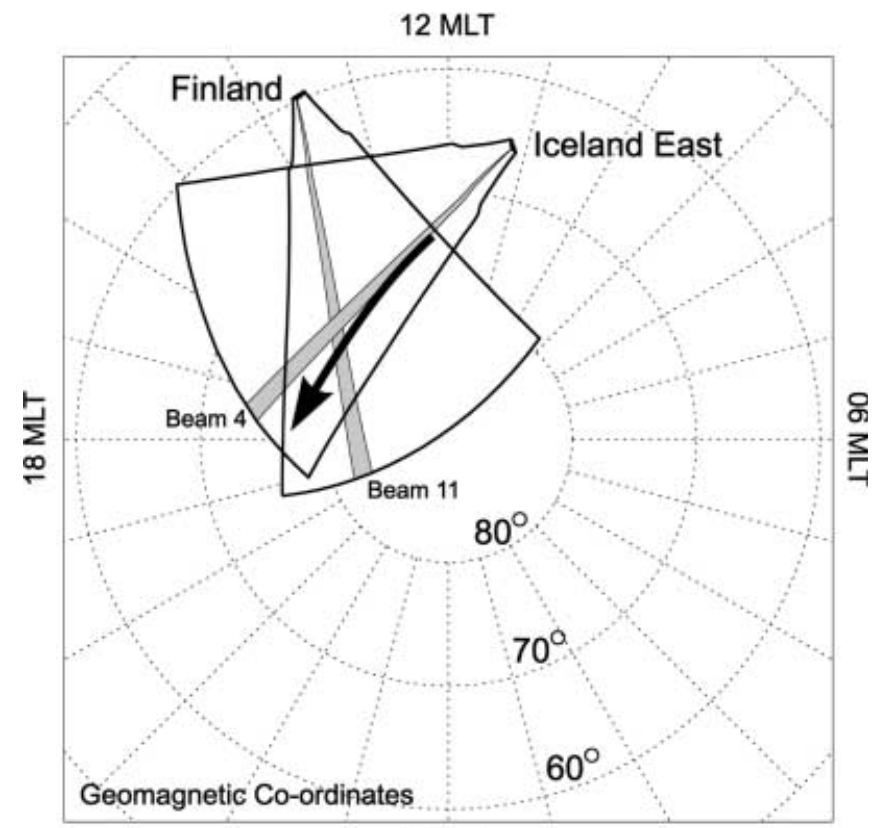

00 MLT

Fig. 1. The CUTLASS radar fields-of-view in the geomagnetic Northern Hemisphere. The pulsed ionospheric flow burst, whose approximate trajectory is marked by an arrow, lasted for half an hour and was tracked through $6 \mathrm{~h}$ of local time 
and the radars in the network are synchronised to perform a full $52^{\circ}$-azimuth scan every minute. A total of 75 range gates are measured along each beam and the range to the first gate is $180 \mathrm{~km}$. The gate length is $45 \mathrm{~km}$ and the typical angular resolution is $4^{\circ}$, or a halfpower beam width of about $100 \mathrm{~km}$ at the half-range mark of $1500 \mathrm{~km}$. The radars were operating at a frequency of about $12 \mathrm{MHz}$, thereby sampling irregularities with wavelengths of approximately $13 \mathrm{~m}$.

For each radar beam a seven-pulse sequence is transmitted. The autocorrelation function of the return signal is analysed to determine several parameters, which form the basis of the data analysed in this study. The backscattered power, the mean Doppler velocity, an estimate of the line-of-sight (LOS) plasma drift velocity, and the width of the Doppler spectrum are determined for each radar range gate.

\section{Observations: 24 November 1998}

\subsection{Upstream solar wind conditions}

At 10:30 UT, the WIND spacecraft was located at (50, $-5,-25) R_{E}$ (GSE). The IMF values from the Magnetic Field Instrument (Lepping et al., 1995) and plasma parameters from the Solar Wind Experiment (Ogilvie et al., 1995) were steady during the preceding several hours. The solar wind speed was approximately $460 \mathrm{~km} \mathrm{~s}^{-1}$ and the proton number density was stable between about 7 and $8 \mathrm{~cm}^{-3}$ throughout the day.

The GSM components of the IMF measured at WIND between 04:00 and 12:00 UT are shown in Fig. 2. The magnitude of the IMF was moderate and very

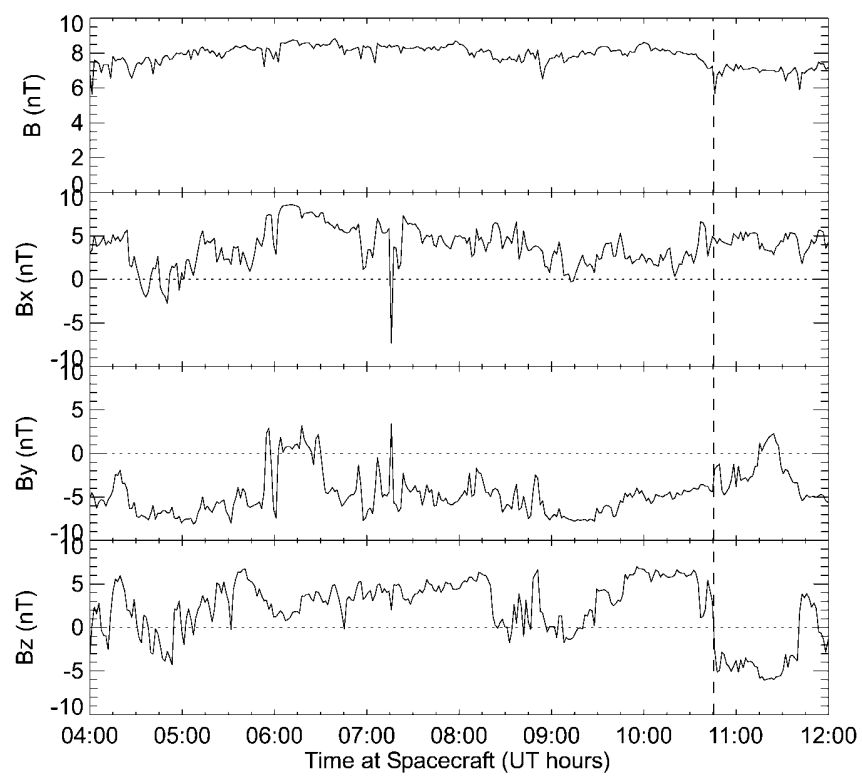

Fig. 2. The magnitude and the GSM components of the IMF measured by WIND, which was located $50 R_{E}$ upstream and $25 R_{E}$ below the ecliptic plane. The time delay from the spacecraft to the ionosphere of the IMF discontinuity measured at 10:45 UT (dashed line) is estimated to be $14 \pm 1 \mathrm{~min}$ steady. The GSM $x$-component of the IMF is strongly positive and steady from about 06:00 UT onwards, with a very brief negative excursion at about 07:15 UT. Between 10:45 and 11:15 UT Bx is $+5 \mathrm{nT}$. The GSM $y$ component of the IMF was steadily negative at about $-5 \mathrm{nT}$ for about $2 \mathrm{~h}$ before 10:45 UT when, over the next half hour, it crept up to zero. The GSM zcomponent of the IMF was strongly northward at $+5 \mathrm{nT}$ for 50 min until, at 10:45 UT, it turned sharply southward and remained at $-5 \mathrm{nT}$ for $50 \mathrm{~min}$. Before the $B z$ discontinuity at $10: 45$, the IMF was mainly northward for $6 \mathrm{~h}$. This led to very quiet magnetospheric conditions at the time of the southward turning, as evidenced by the quiet Dst index, which was within $8 \mathrm{nT}$ of zero for the preceding $24 \mathrm{~h}$. By 13:00 UT, the Dst index had dropped to approximately $-30 \mathrm{nT}$. The $K p$ index between 06:00 UT and 11:00 UT was between $2^{\circ}$ and $2^{+}$, after which time it gradually increased to 4 by 15:00 UT.

We are particularly interested in the southward turning which occurred at 10:45 UT (the vertical dashed line in Fig. 2). The time delay of the southward turning from the spacecraft to the magnetopause was determined using the method of Khan and Cowley (1999). The plane of the discontinuity in the IMF at 10:45 UT was projected back to the GSE $x$ axis, and from there the time delay to the subsolar point on the magnetopause was calculated, using the solar wind plasma parameters. The IMF conditions measured by WIND resulted in a calculated delay of 12 min to the subsolar magnetopause and 2 min were added to account for propagation to the ionosphere (Khan and Cowley, 1999). Therefore the IMF delay to the ionosphere is estimated to be $14 \pm 1 \mathrm{~min}$.

\subsection{CUTLASS ionospheric convection velocities}

In Fig. 3a the backscattered power, (Fig. 3b) LOS velocity, and (Fig. 3c) the spectral width measured by beam 4 of the Iceland East radar are plotted as a function of UT and range in $\mathrm{km}$ from the radar. The backscattered power at a range of approximately $2000 \mathrm{~km}$ in Fig. 3a is less than $20 \mathrm{~dB}$ prior to $10: 58$ UT. Between 10:58 and 10:59 UT the power increases to nearly $30 \mathrm{~dB}$. The timing of this initial response agrees extremely well with the expected response time of 10:59 UT deduced from the solar wind data. The maximum power is observed in the centre of the PIF and is about $40 \mathrm{~dB}$. The power drops below $35 \mathrm{~dB}$ at approximately 11:10 UT and then drops further to $20 \mathrm{~dB}$ by approximately 11:15 UT. There is evidence of a series of 3 PIFs following the southward turning of the IMF with onset times of 10:59, 11:10, and 11:20 UT in Fig. 3a.

The high-velocity anti-sunward flows in Fig. $3 b$ are typical of HF radar PIFs. Negative LOS velocities signify motion away from the radar. The high LOS velocities, in excess of $800 \mathrm{~m} \mathrm{~s}^{-1}$ away from the radar, begin at about 11:06 UT. Because the bistatic vector velocities within the PIF, which will be discussed in detail in Sect. 4.2, have relatively constant magnitudes 
between 11:00 and 11:30 UT, the lack of PIF signature in the LOS velocity data between 10:59 and 11:06 UT is interpreted as a result of radar geometry effects. The PIF propagates away from the radar at a velocity of approximately $800 \mathrm{~m} \mathrm{~s}^{-1}$ along beam 4 . The second PIF started at a slightly closer range of approximately $1800 \mathrm{~km}$, and it propagated away from the radar at similar phase and convection velocities as the first PIF. It is not as distinct as the first PIF, however, and it is only found in the Iceland East data. The third PIF, which appears at approximately 11:20 UT, is very small compared with the previous two and is present in the Iceland East data for only a few minutes.

The lower boundary of the high spectral width region in Fig. 3 decreases in range from approximately $1800 \mathrm{~km}$ to $1400 \mathrm{~km}$ in $15 \mathrm{~min}$. This corresponds to a southward motion of the boundary of the order of $2-3^{\circ}$ in magnetic latitude with respect to a statistical quiet-
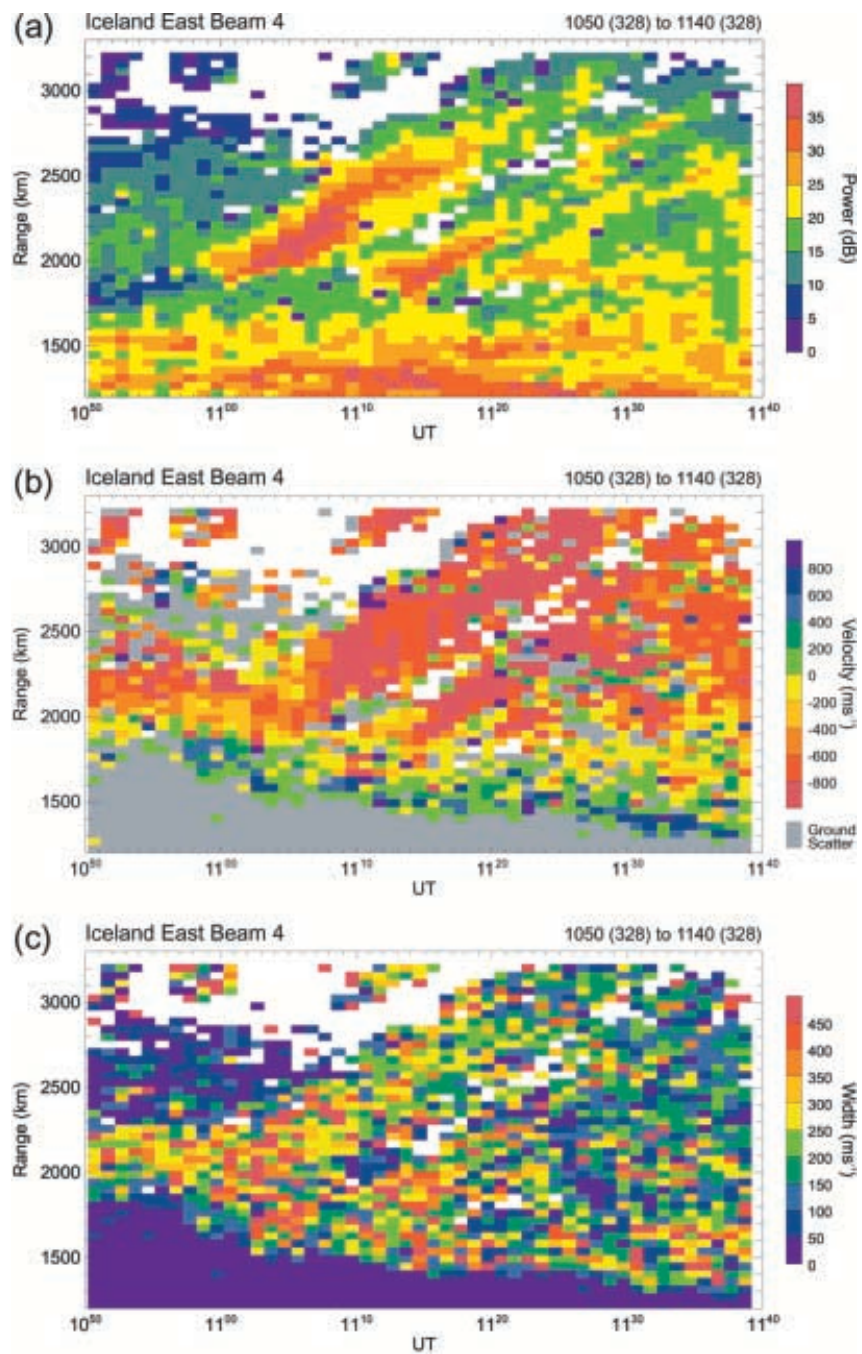

Fig. 3. a Backscattered power, b line-of-sight velocities, and $\mathbf{c}$ spectral widths measured between 10:50 and 11:40 UT by Iceland East beam 4. Negative velocities (red) signify motion away from the radar. The PIF motion was predominantly along Iceland East's western-most beams. The signature of the PIF is therefore much stronger and more well-defined in the Iceland East data time auroral oval. There is evidence of a slight decrease in spectral width within the PIF with increasing range from the radar.

Only the first PIF, which appears at 10:59 UT, is measured by both CUTLASS radars. The PIFs are far less obvious in the Finland data (Fig. 4), because the motion of the PIFs have a much smaller component along the Finland beams. The trajectory of the first PIF, the arrow in Fig. 1, is generally across the Finland beams and in the direction of Iceland East's northernmost beams. In the Finland LOS data in Fig. 4b the PIF is visible as the $-700 \mathrm{~m} \mathrm{~s}^{-1}$ LOS velocity patch centred on approximately $2500 \mathrm{~km}$ range and 11:17 UT. The backscattered power in Fig. $4 \mathrm{a}$ is higher than in the surrounding points, but it is only about $20 \mathrm{~dB}$, not as strong as the Iceland East power. The increase with time of range along the beam of the PIF is consistent with a motion of the PIF away from the radar. At approximately 11:00 UT there is a slight reduction in the range of the lower boundary of the higher spectral width region in Fig. 4c.
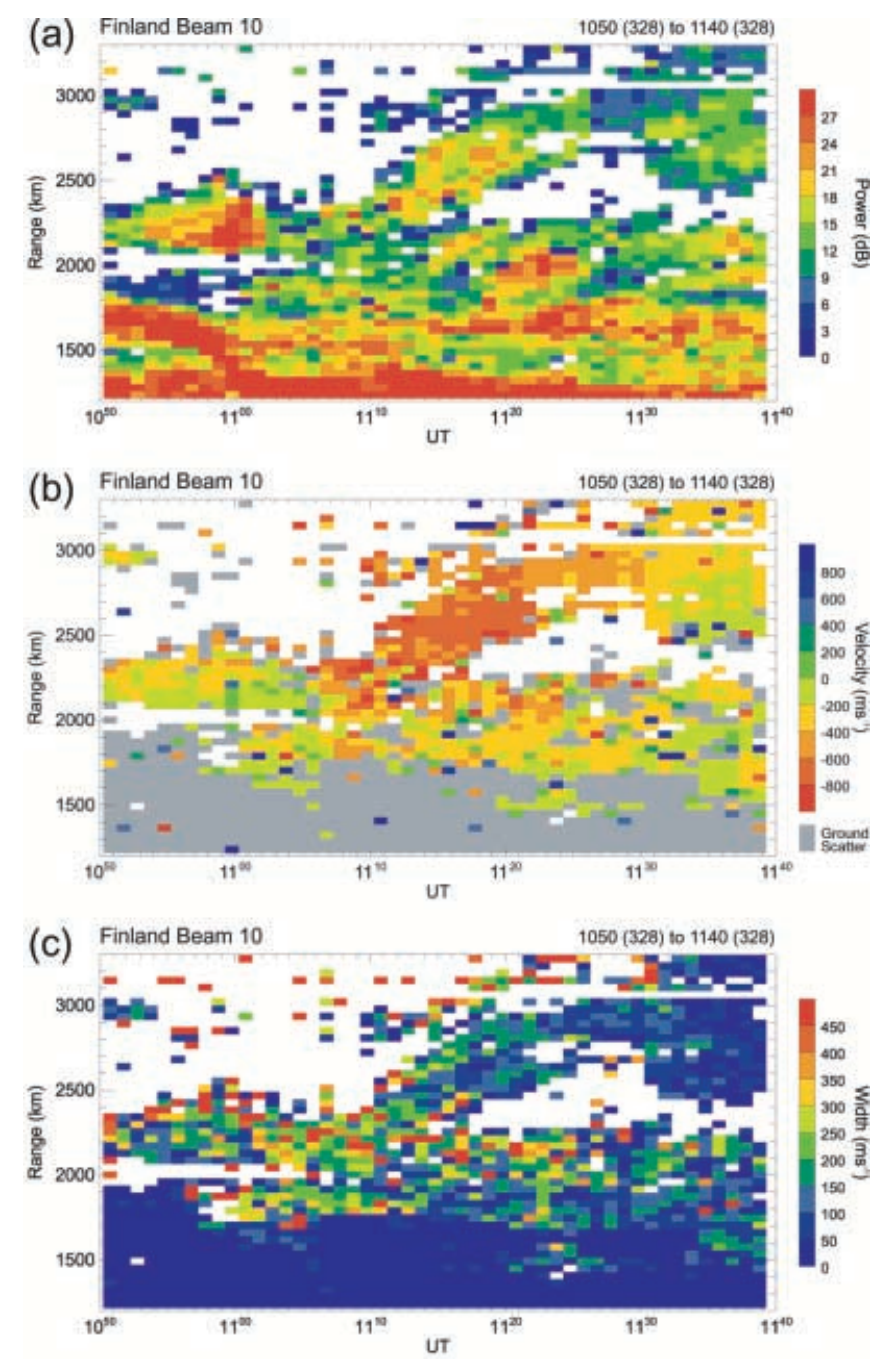

Fig. 4. a Backscattered power, b line-of-sight velocities, and $\mathbf{c}$ spectral widths measured by Finland beam 11 between 10:50 and 11:40 UT. Negative velocities (red) signify motion away from the radar. The PIF motion was predominantly across the Finland field of view 


\subsection{Two-dimensional convection patterns}

The motion of the PIF through the polar cap is much easier to visualise when examined in the context of both radar fields of view. This is a new capability as there exist co-located data from two full radar fields of view. A subset of the radar scans made during the PIF traversal of the Finland and the Iceland East fields of view are shown in Figs. 5 and 6, respectively. The backscattered velocities (colour coded LOS velocities from Finland and Iceland East, and merged vector velocities) are plotted on an MLT versus geomagnetic latitude grid with 12:00 MLT to the top of the plots. To aid the eye, a quiet-time statistical auroral oval has been plotted. Each figure includes four one-minute scans taken at 11:01 UT, 11:06 UT, 11:11 UT, and 11:16 UT. The red patch corresponds to the signature that has been identified as the PIF in the line-of-sight data, e.g. those presented in Fig. 3b. In Figs. 5 and 6 the patch moves from near magnetic local noon towards dusk through the polar cap. The (blue) flows towards the radar between $72^{\circ}$ and $75^{\circ}$ near 1300 MLT in Fig. 6 are consistent with low-latitude sunward return flow of a large-scale convection cell.

The arrows plotted over the LOS data in Figs. 5 and 6 are the merged velocities obtained by reconstructing the 2-dimensional flow vectors from the overlapping single-scan LOS velocities. The merged vectors within the PIF are generally pointed anti-sunward and tend to be located on the leading edge of the PIF. There exist sunward pointing merged velocities between $72^{\circ}$ and $75^{\circ}$ near 1300 MLT, as expected for sunward return flow.

It is useful to examine average merged maps to gain insight into the large-scale flows which are occurring in conjunction with the PIF evolution. The convection maps in Fig. 7 have been produced by averaging LOS velocities both spatially and temporally. Each map shows a 10-min averaged convection map. The grey circles show the location and approximate extent of the PIF measured during the 10 averaged scans. The position and extent of the PIF has been determined from both the backscattered power and the LOS velocity enhancements measured by the CUTLASS radars, like those shown in Fig. 5. The centroid of the region of enhanced power and velocity has been used as the reference point in the study of the PIF motion. The edges of the PIF can be affected by instrumental effects which introduce more uncertainty to the PIF motion. For example, the backscattered power within the PIF decays while the velocity remains high, and therefore choosing a power threshold to define the PIF is not practicable. The sensitivity of the convection velocity to the look direction of the radars makes a velocity threshold impracticable as well. Furthermore towards

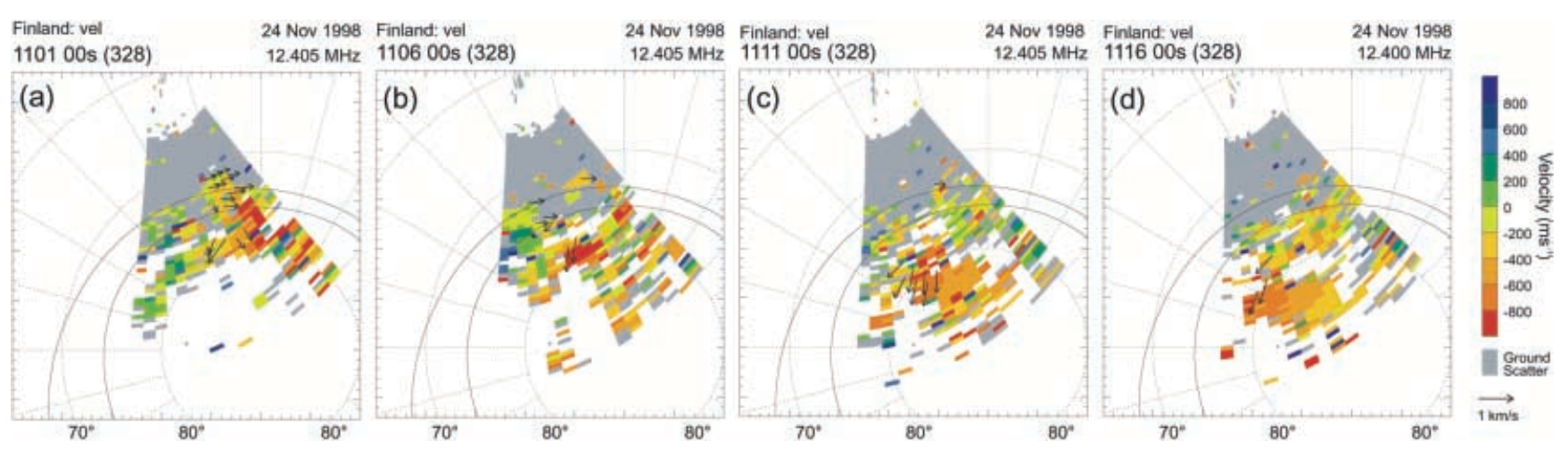

Fig. 5. The progression of the PIF through the Finland radar field of view from the scan taken at 11:01 UT to the scan taken at 11:16 UT at 5-min intervals. The co-ordinates are geomagnetic latitude and MLT with 12:00 MLT toward the top of the plots. The PIF is identified as

the red patch which moves anti-sunward from very near magnetic local noon. The arrows represent the merged ionospheric convection velocity vectors obtained by reconstructing the 2-D vector from the line-of-sight measurements from Iceland East and Finland

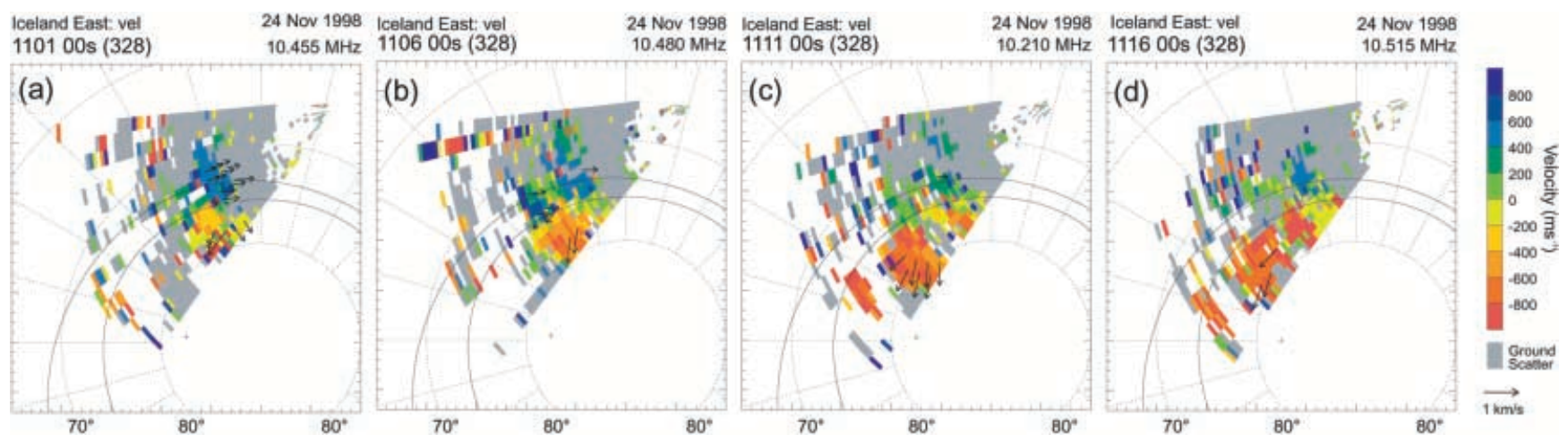

Fig. 6. The progression of the PIF through the Iceland East radar field-of-view in the same format as Fig. 5 
(a) 11:00-11:10 UT

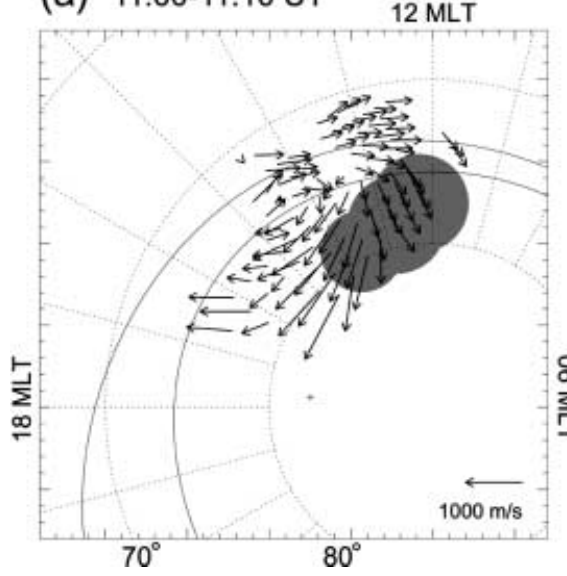

(b) $11: 10-11: 20$ UT

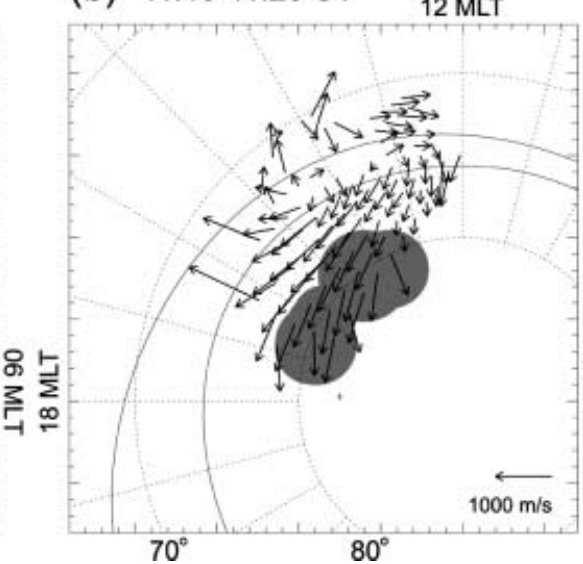

(c) $11: 20-11: 30$ UT

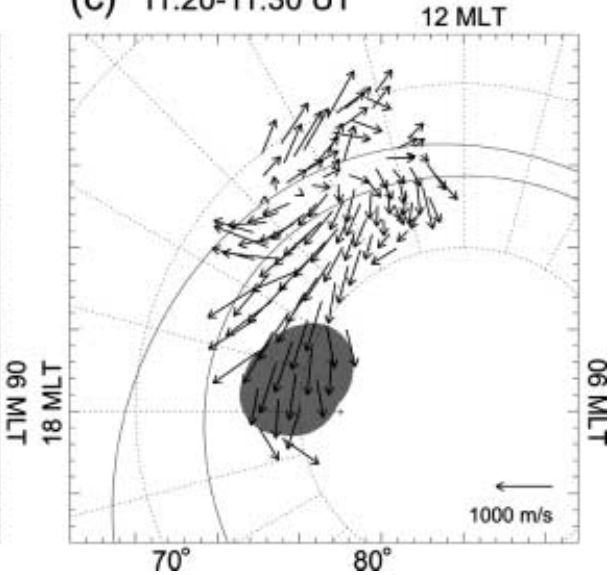

Fig. 7. Plots of 10-min averages of the convection excited in the ionosphere in response to a southward turning of the IMF at 10:59. The arrows are the two-dimensional measured convection velocities averaged over ten one-minute radar scans. The grey circles represent the approximate locations and extents of the PIF during each $10 \mathrm{~min}$ interval the end of the interval the position of the leading edge of the PIF suffers from very long propagation paths and therefore higher uncertainty in position. More events of this type will need to be examined in order to determine more precisely the details of the PIF motion. In general, the PIF is located on the poleward edge of the measured convection pattern, which appears to expand azimuthally in concert with the motion of the PIF (Fig. 7). There is evidence of a convection reversal boundary on the southern part of the convection patterns near approximately $73^{\circ}$ magnetic latitude.

\section{Discussion}

Because of the steadily northward IMF conditions and the weak geomagnetic activity preceding the southward turning at 10:45 UT, a quiet magnetosphere is expected. The CUTLASS radars are therefore expected to mon- itor an isolated ionospheric response to the southward turning of the IMF, which is expected to affect the ionosphere at 10:59 UT. We have studied the trajectory of an HF radar PIF and the development of convective flows in the ionosphere that arise subsequent to the southward IMF turning. These measurements of ionospheric convection throughout the PIF signature offer a hitherto unique perspective on the ionospheric response to magnetopause reconnection.

\subsection{PIF trajectory}

We determined the PIF trajectory by estimating the motion of the centre of the region of high-velocity and high-power radar backscatter. Measurements from both CUTLASS radars were used to determine the location of the centre of the PIF. Figure $8 \mathrm{a}$ summarises the motion of the PIF. The black dots mark the central
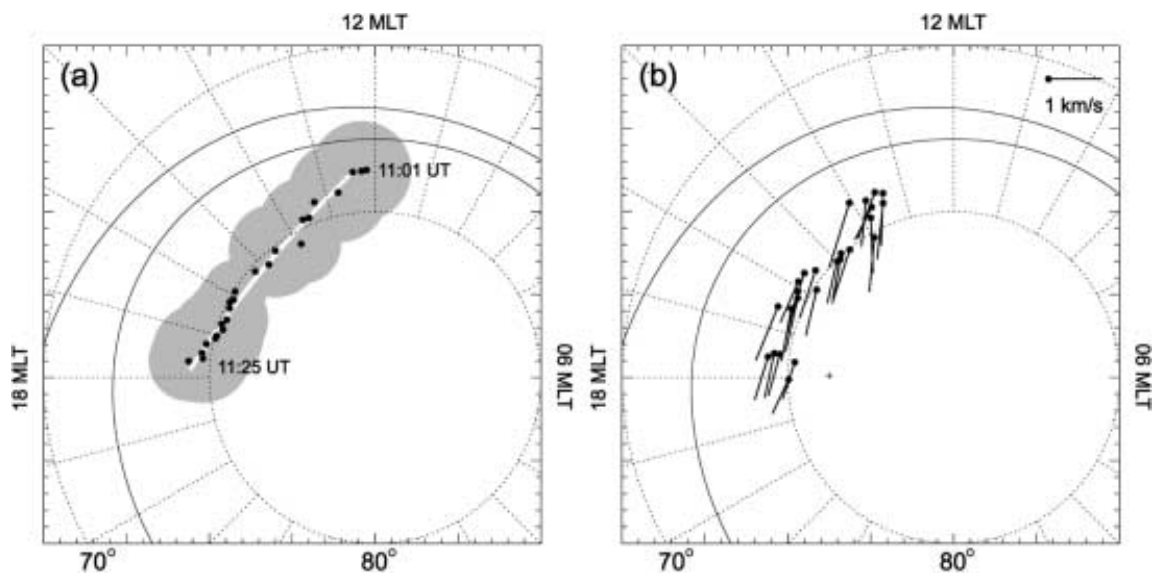

Fig. 8. a The PIF originates very close to magnetic local noon. The small black dots mark the central PIF position, and the large grey circles represent the approximate extent of the PIF as it moves from noon to dusk. The white line is the best fit geodesic curve to the PIF central position. b The average merged convection velocity measured within the PIF. The averaged position of the merged vectors in the PIF (different than the estimated PIF centre) is represented by the black dot and the direction and magnitude of the convection velocity is represented by the line. The convection is generally anti-sunward and eastward 
position of the PIF. The large circles are an estimation of the location and extent of the PIF in the radar fields of view. The PIF progresses in a very orderly manner from noon to dusk. The first clear evidence of the PIF in the radar scans is found at 11:01 UT near magnetic local noon with the centre shifted slightly postnoon. This was unexpected since the effect of the negative $y$ component of the IMF is expected to shift the cusp footprint away from noon into the morning sector (Cowley et al., 1991). The PIF moves from noon to the dusk meridian where it becomes less distinct and begins to move out of the radar fields of view. After 11:26 UT, the central position of the PIF can no longer be accurately determined. The duskward motion of the PIF is consistent with its following the ionospheric convection influenced by the negative IMF By orientation during this interval, which tilts the anti-sunward flow eastward in the Northern Hemisphere. The PIF appears to follow the shortest possible path through the ionosphere. The solid white line in Fig. 8a is the best fit geodesic curve at ionospheric altitudes to the trajectory of the PIF centre. The trajectory of PIF 2 (not shown), as determined solely from the Iceland East data, follows a similar path as PIF 1 , starting near magnetic local noon, but approximately $2^{\circ}$ equatorward of the PIF 1 trajectory.

\subsection{Convection within the PIF}

For each one-minute radar scan the merged velocity vectors that fell within the PIF were averaged in order to estimate the convection velocity within the PIF. Vectors representing the mean plasma convection velocity are plotted in Fig. 8b. The dots represent the centroid of the averaged merged vectors within the PIF signature. This is, in general, different from the estimated PIF centre as the vectors tend to be in the leading portion of the PIF. The lines represent the magnitude and the direction of the averaged convection velocity. The mainly antisunward convection velocity initially has a poleward component. The plasma convection then rotates through eastward and ends up with a small southward component. This is consistent with PIF motion in the poleward part of a large-scale postnoon convection cell.

Previous radar studies of PIFs have relied on single measurements from which convection velocities have been inferred (e.g. Provan et al., 1998). The bistatic measurements in this event allow us, for the first time, to compare the measured convection velocity within the PIF to the phase motion of the PIF as it progresses through the polar cap. The phase velocity is determined by comparing the PIF centre positions for successive scans.

In Fig. 9a we compare the magnitude of the convection velocity measured within the first PIF with the phase speed of the PIF itself. The phase speed errors have been determined assuming an error in the determination of the central PIF position by one radar range cell. The ionospheric convection speed (thick line) is very stable throughout the PIF lifetime. Chisham et al. (2000) also found that the convection speed in the initial
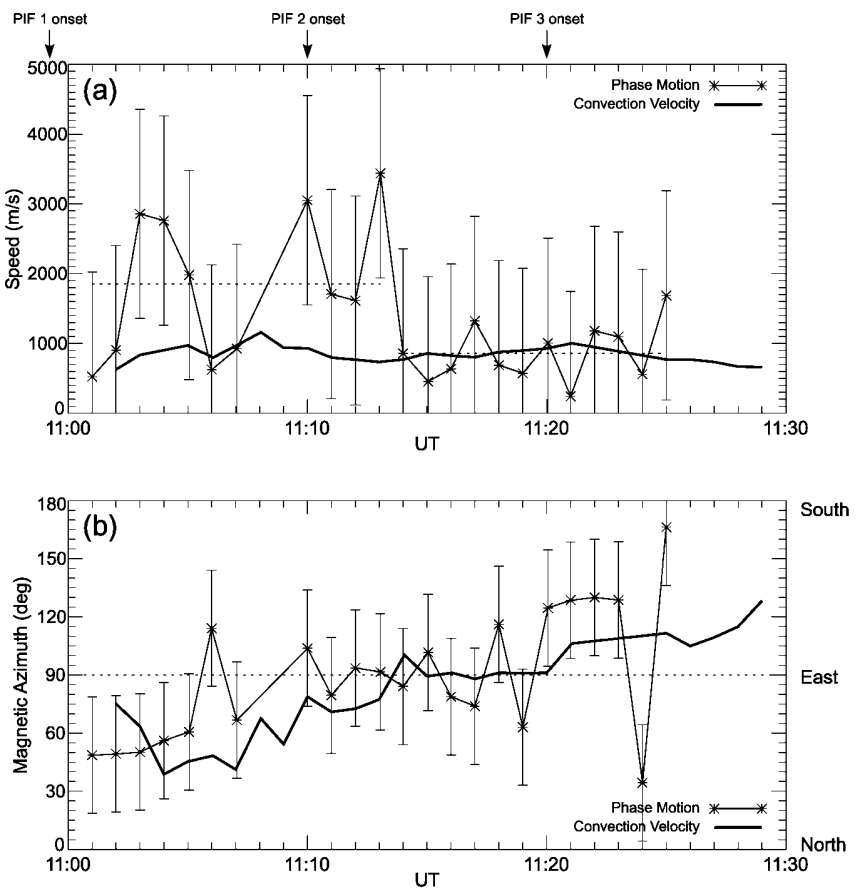

Fig. 9. A comparison of $\mathbf{a}$ the speed and $\mathbf{b}$ the direction of measured $\mathbf{E} \times \mathbf{B}$ drift (thick line) within the PIF and the phase velocity (thin line with asterisks) of the PIF. The phase speed appears to have two regimes, one of fast, highly variable speeds, and subsequently one where the phase and convection speeds are nearly identical. The two dotted lines in a represent the mean phase speed of the two different regimes: $1850 \mathrm{~m} \mathrm{~s}^{-1}$ and $870 \mathrm{~m} \mathrm{~s}^{-1}$

part of PIF evolution at one location was stable. The stability of the convection speed into the polar cap may be due to the strong IMF $B_{y}$ control of the convection pattern. The convection stream lines, or equivalently the equipotential contours, are pushed over into the postnoon sector, and they remain quite evenly spaced. This implies a uniform electric field and therefore a constant convective speed. The phase velocity (thin line with error bars), on the other hand, appears to have two main stages. During the first $12 \mathrm{~min}$, the phase speed is fast and highly variable. The mean phase speed of $1850 \mathrm{~m} \mathrm{~s}^{-1}$ (denoted by a dashed line) is roughly twice the mean convection speed of $870 \mathrm{~m} \mathrm{~s}^{-1}$ during this interval. The mean phase speed falls within the error bars for all but the last high speed point, which is very close. These error bars do not systematically include, however, the convection speed, and therefore we conclude that the difference between the phase speed and the convection speed is significant. After 11:14 UT the phase speed becomes much more stable and slows down to an average value of $870 \mathrm{~m} \mathrm{~s}^{-1}$ (denoted by a dashed line). This is close to the average convection speed of $840 \mathrm{~m} \mathrm{~s}^{-1}$ measured during this interval, and within the estimated phase speed error. The onset times for the last two PIFs are marked at the top of Fig. 9a.

The magnetic azimuth of the phase and convection velocities is presented in Fig. $9 \mathrm{~b}$, where $0^{\circ}$ is north, $90^{\circ}$ is east, and so on. The thin line with error bars is the azimuth of the phase velocity and the thick line is the azimuth of the convective plasma flow. The phase 
velocity azimuth error has been estimated by assuming, as for the phase speed error, that the error in the PIF central position was one range cell. As previously noted, the mainly anti-sunward convection velocity initially has a northward component, then rotates through eastward, and finally has a southward component, consistent with convective flows in the poleward portion of a large-scale postnoon convection cell. The phase velocity of the PIF also exhibits the same behaviour, and, with the exception of three points, the phase velocity azimuth agrees within error with the convection velocity azimuth.

The difference between the phase speed of and the convection speed within the PIF during the first phase of the PIF motion implies that this is an interval of active magnetic reconnection, while the second phase of PIF motion is believed to be an interval of anti-sunward convection, since the convection and phase speeds are nearly identical. The second PIF appears near magnetic local noon at 11:10 UT, 3 min before reconnection has ceased in the first PIF, implying that, during this interval, reconnection is continually occurring but at different locations on the magnetopause. The trajectory of PIF 2 began near magnetic local noon and followed a similar path to PIF 1 but approximately $2^{\circ}$ equatorward, as expected for a subsequent interval of reconnection.

The backscattered power in Fig. 3a supports the reconnection followed by convection hypothesis deduced from the velocity data. The backscattered power begins to decay at approximately 11:15 UT, whereas the LOS velocities remain strongly antisunward until 11:30 UT. The loss of power is consistent with loss of an Fregion precipitation source, as is typical of the cusp (Yeoman et al., 1997) and the subsequent decay of the irregularities within the PIF. There is also a trend of decreasing spectral widths during the PIF lifetime seen in both Iceland East and Finland data (see Figs. 3c and 4c). The spectral widths measured by beam 4 of the Iceland East radar (Fig. 3c) during the first PIF, for example, decrease by about $200 \mathrm{~m} \mathrm{~s}^{-1}$. When a Doppler spectrum is wide, it is a result of the presence of many frequencies in the sample, i.e. a highly turbulent medium. A decreasing spectral width, as is the case in the CUTLASS data, is indicative of a reduction in the turbulence of the sampling volume (Andre et al., 1999), as would be expected with the removal of the source of the F-region irregularities.

The hypothesis of a interval of reconnection followed by an interval of convection during a PIF can be interpreted in the context of the predicted ionospheric response (Cowley et al., 1991; Lockwood et al., 1993; Lockwood, 1994) and of the joint observations by HF radar and ultraviolet images of the aurora presented of Milan et al. (2000). A model of the ionospheric response to reconnection during negative IMF $B_{y}$ conditions is illustrated in Fig. 10, after Milan et al. (2000). During an episode of reconnection, when the IMF $B_{y}$ component is negative, a region of newly opened flux (dark grey region) is appended to the polar cap adjacent to the open-closed field line boundary (OCFLB), as shown in Fig. 10a. Initially the $B_{y}$ tension force acts in such a
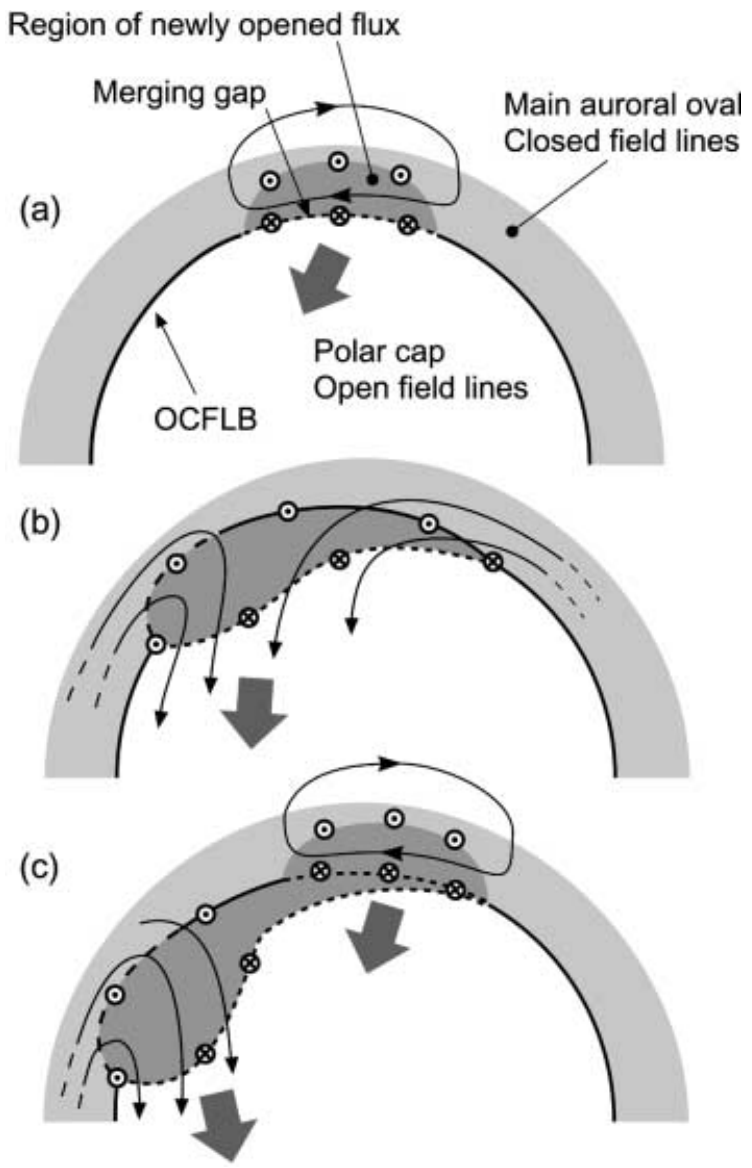

Fig. 10a-c. A schematic diagram illustrating a model of the ionospheric response to the addition of open flux to the polar cap during an episode of flux transfer at the magnetopause when IMF $B_{z}<0$ and $B_{y}<0$, after Milan et al. (2000). The light grey region represents the main auroral oval on closed field lines and is separated from the polar cap by the open-closed field line boundary (OCFLB). a The dark grey shaded area represents the region of newly created open flux. The predicted upward and downward field-aligned currents are shown as the circled dots and crosses, respectively. The plasma convection is denoted by curved arrows. b The reconnection site propagates azimuthally away from local noon, creating open flux away from the noon sector. $\mathbf{c}$ The second episode of reconnection begins near noon while the first reconnection site continues to propagate away from noon

manner as to pull the flux tubes duskward. Once the reconnection-induced kink in the newly opened field lines has been straightened out, the anti-sunward flow in the magnetosheath draws the flux tubes anti-sunward. This gives rise to the convection flows shown in Fig. 10b. The azimuthal propagation of the reconnection site will continue to add open magnetic flux to the polar cap as the reconnection site propagates away from the initial reconnection site. The convection excited in the ionosphere flows in such a manner as to assimilate the newly opened flux into an expanded polar cap. The implications of the field-aligned current distribution and the relative locations of auroral emissions and radar PIFs will be discussed in a companion paper comparing the current radar PIF observations and global ultraviolet auroral emissions. 
Despite the azimuth of the convection velocity agreeing within error with that of the phase velocity, there is a trend for an azimuth offset throughout the PIF's lifetime, which cannot be conclusively determined in this study. There also appears to be a change in the PIF area during its lifetime. During the last half of the interval, when reconnection is believed to have ceased and the reconnected flux tubes are simply convecting with the solar wind, the area of the high-velocity region of backscatter gradually increases. By accounting for the change in area and the alteration of the central PIF position, the $15^{\circ}$ azimuth offset, for the most part, can be accounted for. The measured area of the PIF is simply the target of ionospheric irregularites within the region of reconnected flux that is presented to the radars. If the distribution of irregularities is nonuniform within the footprint of a flux transfer event, the PIF area may appear to change (e.g. see Rodger et al., 1994). If the irregularities initially appear near the leading edge of the PIF and then proceed to expand through the entire PIF, this would lead to an apparent change in the phase velocity of the PIF. The tendency of the merged convection velocities to be in the leading portion of the PIF may also be due to such a process. More events of this type will need to be studied and more definitive methods developed to determine the extent of the PIF, and to determine whether the azimuthal offset is significant above the errors and is a consistent feature of a PIF.

\subsection{Implications for reconnection at the magnetopause}

The extended interval of reconnection deduced from ionospheric observations has important implications for the nature of reconnection at the magnetopause. We can estimate roughly the size of the reconnection region at the magnetopause using a simple dipole model. During the first few minutes the PIF area in the ionosphere is approximately $2.4 \times 10^{5} \mathrm{~km}^{2}$. Flux conservation for a simple dipole field maps the PIF to a cross sectional area of about $2 R_{E}^{2}$ in the equatorial plane at $10 R_{E}$, with a radial extent of approximately $0.5 R_{E}$ and an azimuthal extent of approximately $4 R_{E}$. The initial reconnection region on the magnetopause is illustrated as the darkened region in Fig. 11a. In the ionosphere this corresponds to the situation presented in Fig. 10a. This region of active reconnection then propagates azimuthally along the magnetopause, continually creating open field lines, which thread the magnetopause. This gives rise to the peeling of flux from the magnetopause, represented by the large grey-shaded region in Fig. 11b. If the reconnection site also propagated into the morning sector, this shaded region would form a closed loop around the initial reconnection site. In the present study the second flux transfer event is believed to commence $11 \mathrm{~min}$ after the first, before the first episode of reconnection ended. The second flux transfer event is the small shaded area in Fig. 11b. This second reconnection site will then propagate azimuthally, as did the first, peeling another layer of flux from the magneto-
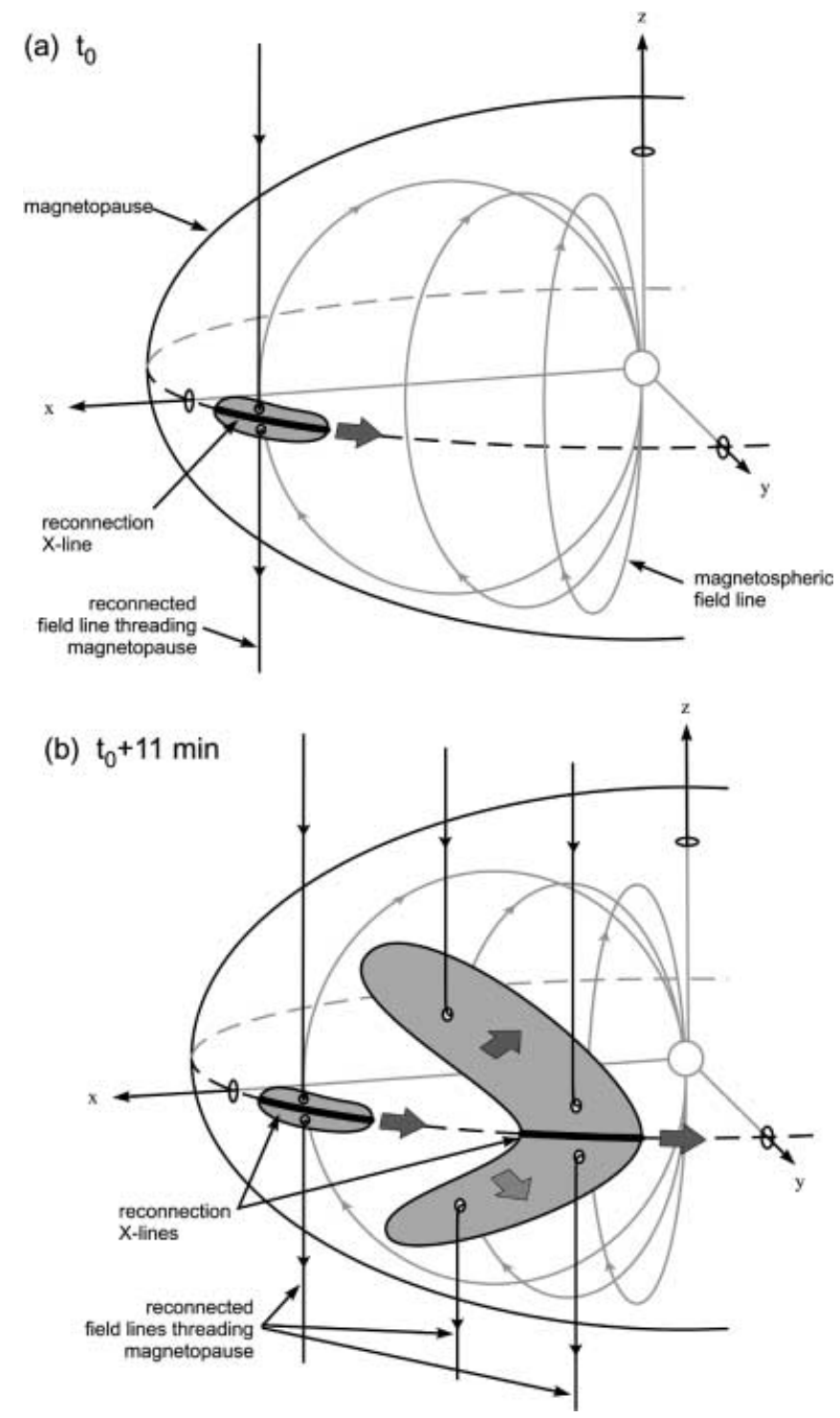

Fig. 11a, b. A schematic model of the azimuthal a propagating reconnection region on the magnetopause. a The shaded area represents the initial magnetopause region through which newly opened flux tubes thread. This magnetospheric configuration corresponds to the ionospheric response illustrated in Fig. 10. The propagation of the first reconnection site will result in a large area of the magnetopause threaded by open field lines, which is represented by the large shaded area in $\mathbf{b}$. The second flux transfer event, the small shaded area in $\mathbf{b}$, occurred $11 \mathrm{~min}$ after the onset of the first

pause. This magnetospheric configuration is predicted to map down to the ionospheric configuration presented in Fig. 10c.

This reconnection model is supported by the magnetospheric model of Tsyganenko (1989). The first few PIF central positions map out to the magnetopause and the field lines progress from very near noon towards dusk. The motion of these modelled field lines is far in excess of the shocked solar wind speed in the sheath, lending support to the hypothesis that the PIF is initially the footprint of a region of active reconnection. The remaining field lines then map to the mantle where they straighten out and convect deeper into the magnetotail. 
Magnetopause uncertainties make it increasingly difficult to determine the velocity of the field line at the magnetopause during the latter part of the PIF evolution, but it appears to be consistent with the solar wind convection to $50 R_{E}$ when reconnection ceases and to $125 R_{E}$ when the PIF leaves the radar field of view.

\subsection{Cross-polar cap potential difference and reconnection voltage}

The comparison of the phase motion of and the convection velocities within the PIF has indicated that magnetic reconnection on the dayside lasts for several minutes and that the magnetopause reconnection region expands azimuthally during the first phase of the PIF development. The vector measurements and the Northern Hemisphere SuperDARN array offer two techniques to estimate the flux addition to the polar cap during the series of three PIFs measured by the radars. The size and trajectory of the PIF during the reconnection phase is an estimate of the size of the reconnection X-line mapped down into the ionosphere. The convection velocity can be transformed into the reference frame of the reconnection X-line since the motion of the spectral width boundary gives an estimate of the motion of the reconnection X-line in the Earth's reference frame. (See Lockwood and Cowley, 1992, for further discussion of the ionospheric projection of the reconnection Xline.) After the IMF turns southward, the equatorward boundary of the spectral width responds and moves equatorward. We have determined from the spectral width boundary that the ionospheric projection of the $\mathrm{X}$-line moves a total $400 \mathrm{~km}$ in $15 \mathrm{~min}$, during which time there is evidence of three PIFs in the Iceland East data. The boundary is not well enough defined to distinguish between reconnection events, so we will estimate the amount of flux added over the entire $15 \mathrm{~min}$ interval where the spectral width boundary is moving.

The reconnection scenario we have assumed is illustrated in Fig. 12. The average ionospheric convec-

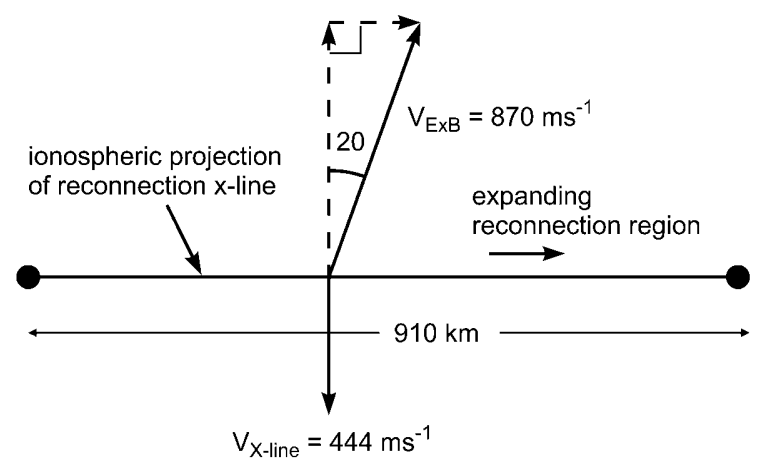

Fig. 12. The estimated ionospheric projection of the azimuthally propagating reconnection $x$-line that covers a distance of $910 \mathrm{~km}$ in total and has an equatorward velocity of $444 \mathrm{~m} \mathrm{~s}^{-1}$. The plasma convection velocity $V_{E \times B}$ in the PIF is $870 \mathrm{~m} \mathrm{~s}^{-1}$ and is directed, on average, $20^{\circ}$ from the $x$-line normal direction during the interval of reconnection tion velocity measured during the interval of magnetic reconnection, $V_{E \times B}$, is $870 \mathrm{~m} \mathrm{~s}^{-1}$ anti-sunward, and the equatorward velocity of the reconnection $\mathrm{X}$-line, $V_{X \text {-line }}$, is approximately $444 \mathrm{~m} \mathrm{~s}^{-1}$. The plasma convection is directed, on average, $20^{\circ}$ eastward of the X-line normal direction. Therefore the convection velocity in the frame of reference of the reconnection X-line is $1260 \mathrm{~m} \mathrm{~s}^{-1}$. We estimate the full extent of the X-line measured by the radars to be approximately $910 \mathrm{~km}$, from the easternmost point at the onset of the PIF to the westernmost point at the end of the interval of reconnection. The voltage across the X-line, $\Phi_{d a y}$, can be estimated in the ionosphere to be:

$\Phi_{d a y}=B v^{\prime} L$

where $B$ is the magnitude of the geomagnetic field in the ionosphere, $v^{\prime}$ is the plasma velocity in the reconnection $\mathrm{X}$-line reference frame, and $L$ is the length of the reconnection X-line mapped down to the ionosphere. In our case, the voltage drop along the X-line is estimated to be $57 \mathrm{kV}$. It is important to note that we have not included any contribution from the possible expansion of the X-line into the morning sector since we have no radar measurements in that area. It is therefore possible that the total voltage drop is underestimated.

The substorm activity on the nightside during the interval of interest can be monitored by both auroral images and Pi2 activity on the ground. There is very little activity in the substorm sector as evidenced by Polar UVI (Torr et al., 1995) and VIS (Frank et al., 1985) Earth Camera images of the nightside. The images of the ultraviolet aurora (not shown) display weak auroral activity on the nightside before 12:00 UT. The CANOPUS magnetometer (Rostoker et al., 1995) at the Dawson City station (magnetic latitude $66.06 \mathrm{~N}$; magnetic longitude: $-88.68 \mathrm{E}$ ) is located in the midnight sector (between 2300 and 0100 MLT). The magnetometer measured intervals of light Pi2 band activity during the day; the ground magnetic deflections filtered between 20 and $200 \mathrm{~s}$, measured from 09:00 to 15:00 UT, are shown in Fig. 13. Before 12:00 UT there are small bursts of Pi2 band activity. These are accompanied by weak auroral emissions on the nightside which do not develop into substorms. There is a larger Pi2 just after 12:00 UT at which time the VIS Earth Camera and UVI both measured a substorm on the nightside. The Dawson City magnetometer is located directly underneath the westward travelling surge. From the nightside activity, we believe that there is no significant loss of open flux and hence no significant nightside contribution to the potential drop in the polar cap before 12:00 UT. Therefore we estimate that the cross-polar cap potential difference during our interval of dayside reconnection is $57 \mathrm{kV}$.

The cross polar cap potential difference can also be determined using spherical harmonic expansions to fit ionospheric convection velocities from six of the Northern Hemisphere SuperDARN radars using the method of Ruohoniemi and Baker (1998). This method of potential fitting results in a global-scale potential map of the northern magnetic pole region. Two sample iono- 

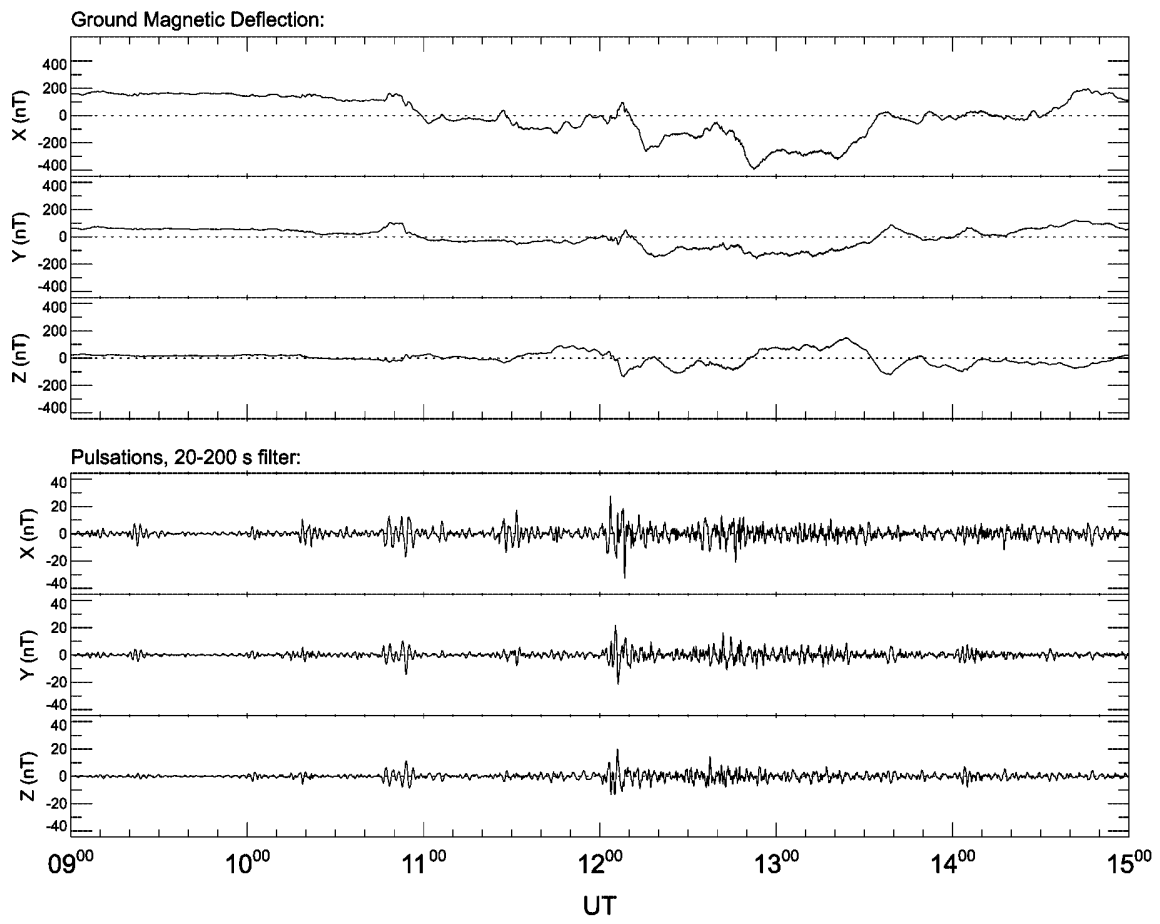

Fig. 13. The $x, y$, and $z$ components of the ground magnetic deflections and the $\mathrm{Pi} 2$ pulsations, filtered between 20 and $200 \mathrm{~s}$, measured between 09:00 and 15:00 UT by the CANOPUS magnetometer station at Dawson City, which is in the midnight sector spheric equipotential contour maps are presented in Fig. 14. The ionospheric convection pattern (equipotential contours) in Fig. 14a are calculated from ionospheric convection velocities measured approximately $20 \mathrm{~min}$ prior to the southward IMF turning. The flows in the ionosphere are very weak with no obvious twin-cell convection pattern, and the cross polar cap potential difference is relatively low, $26 \mathrm{kV}$. The fit to the convection velocities measured between 11:01 and 11:02 UT, approximately three minutes after the southward IMF turning is expected to reach the ionosphere, is plotted in Fig. 14b. A very distinct twin-cell convection pattern has been established, with a higher cross-polar cap potential difference of $64 \mathrm{kV}$.

The cross-polar cap potential difference for each radar scan has been calculated between 10:00 and 12:00 UT, and the results are presented in Fig. 15. The map potential model requires information on the IMF orientation in order to determine the statistical convection pattern used to constrain the fit to the data. The cross-polar cap potential difference has been calculated in two ways: (1) using a fixed IMF and (2) using the IMF data from the WIND spacecraft, in an attempt to determine any dependence on the statistical convection pattern used to constrain the fit. The uncertainty in the value of the cross-polar cap potential difference is larger prior to 11:00 UT, since there was less radar backscatter, and therefore fewer data points to include in the fit. The $26 \mathrm{kV}$ voltage determinination prior to 11:00 UT is expected to be an over-estimate since the fitting procedure is constrained by a statistical model which tends towards a non-zero voltage convection pattern. Both potential fits show a jump in the cross-polar cap potential difference at approximately 11:00 UT, with the fit constrained by the IMF data from WIND having a larger polar cap potential difference. The cross-polar cap potential difference between 60 and $70 \mathrm{kV}$ obtained from the map potential model agrees very well with our previous estimate of $57 \mathrm{kV}$, in which we considered the size and motion of the ionospheric reconnection $x$-line in the afternoon sector.

\subsection{Large-scale convection and comparison with satellite measurements of the optical aurora}

The PIF originally appears near magnetic local noon on the poleward boundary of the UV aurora measured by the Polar VIS Earth Camera. The PIF then moves antisunward and progresses further into the polar cap, leaving the radar fields of view at 1800 MLT several degrees poleward of the poleward edge of the UV auroral emissions. The UV aurora appears to evolve in conjunction with excited plasma flows near the convection reversal boundary. This is consistent with the afternoon upward region 1 field-aligned current. In the 14 MLT sector there is pulsing of the UV aurora, which appears to be related to the passage of the series of PIFs into the polar cap. The relationship between the radar PIFs, the UV aurora, and the field-aligned currents will be examined in detail in a companion paper.

\section{Comparison to previous work}

Following the southward turning of the IMF at 10:45 UT, a series of poleward moving transients were measured by CUTLASS starting at 10:59, 11:10 and 11:20 UT. The response time agreed with the delay to the ionosphere predicted by the method of Khan and Cowley (1999). The repetition rate of the PIFs falls in the longer period portion of the PIF distributions found by McWilliams 
(a)

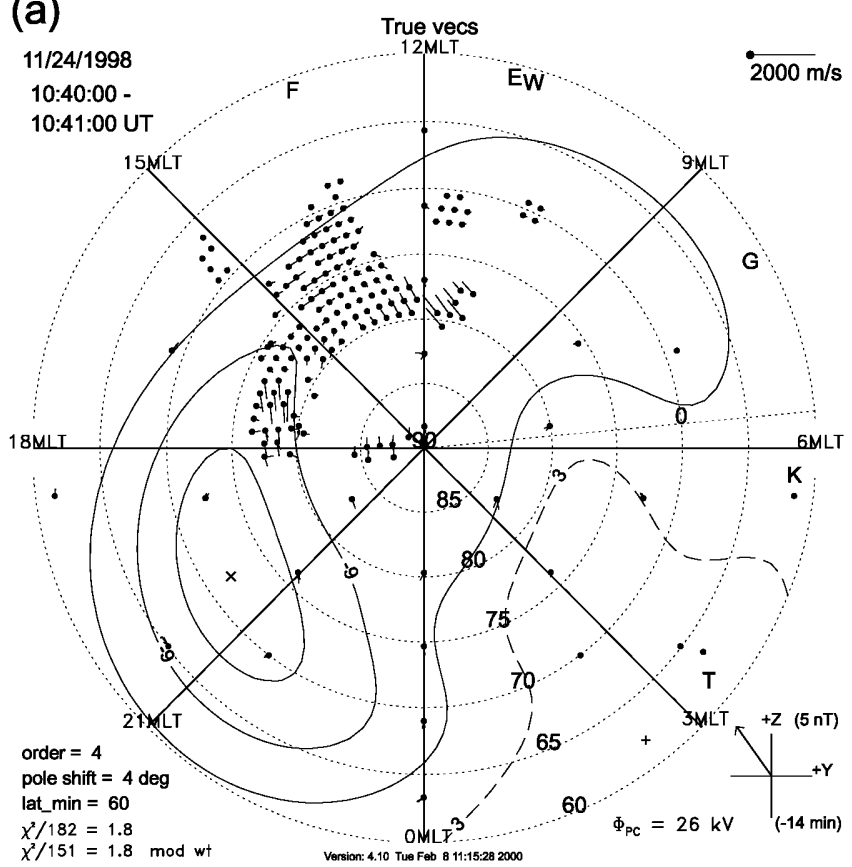

Fig. 14a, b. Equipotential contours deduced from SuperDARN data from six Northern Hemisphere radars according to the method of Ruohoniemi and Baker (1998) a at 10:40 UT, prior to the southward

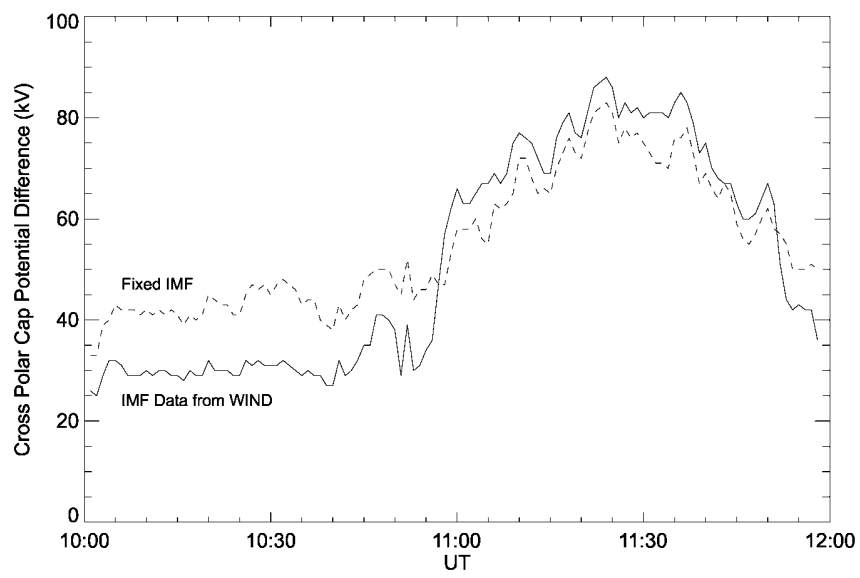

Fig. 15. The cross polar cap potential difference as determined from the spherical harmonic fit to line-of-sight velocity data from six Northern Hemisphere SuperDARN radars according to the method of Ruohoniemi and Baker (1998). The potential fits were constrained by statistical ionospheric convection patterns, one calculated with a constant IMF value and the other deduced using IMF values from WIND

et al. (2000) in their statistical study of PIFs observed in data from the CUTLASS Finland radar.

The first PIF is monitored for half an hour by both radars and is the subject of the detailed analysis presented here. The bistatic measurements of the ionospheric plasma convection within the PIF have allowed for an unprecedented comparison of the phase and convection velocities associated with the PIF. The convection velocity within the PIF was very stable at about $850 \mathrm{~m} \mathrm{~s}^{-1}$ throughout the PIF's traversal of the (b)

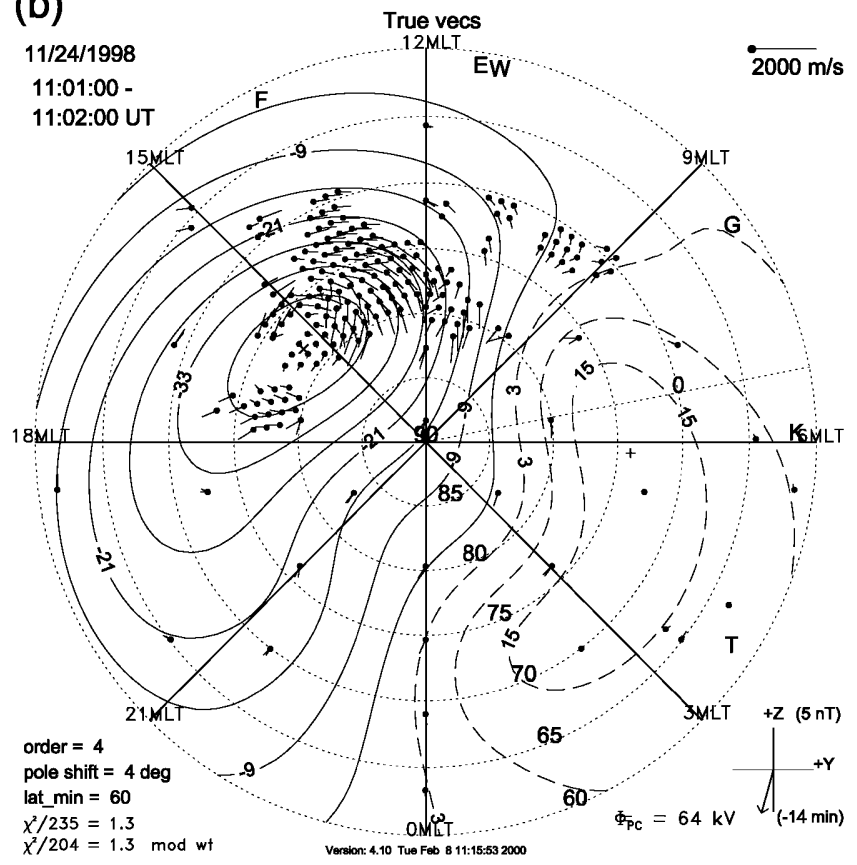

IMF turning and $\mathbf{b}$ at 11:01 UT, just shortly after the southward IMF turning

radar fields of view. In contrast, the phase velocity had two main stages. During the first stage, the mean phase speed was $1850 \mathrm{~m} \mathrm{~s}^{-1}$, approximately twice the convection speed. The second stage saw the phase speed slow down to nearly the convection speed.

Previous attempts have been made to estimate the convection velocity within a radar PIF. Using a beamswinging technique, Provan et al. (1998) estimated that the convection speed within their PIF was roughly $2000 \pm 500 \mathrm{~m} \mathrm{~s}^{-1}$. The comparison by Neudegg et al. (1999) found radar velocity enhancements along a beam of $1000 \pm 200 \mathrm{~m} \mathrm{~s}^{-1}$ and $1500 \pm 200 \mathrm{~m} \mathrm{~s}^{-1}$ associated with measured FTEs at the magnetopause. The poleward velocity within the radar PIF found by Milan et al. (2000) was $1.3 \mathrm{~km} \mathrm{~s}^{-1}$; this occurred during very disturbed conditions when the IMF had a strong southward component, reaching $-13 \mathrm{nT}$. The previous results are all larger than the average convection speed of $850 \mathrm{~m} \mathrm{~s}^{-1}$ in the present study.

Due to the limited viewing area of previous studies of radar PIFs, which utilised data from one or two radar beams, it has been very difficult to determine the phase motion of a PIF. Provan et al. (1998) attempted to determine the phase velocities of PIF signatures by taking advantage of high-time resolution measurements along two beams of the CUTLASS Finland radar that were separated in azimuth by $23^{\circ}$. The phase speed was estimated by comparing the PIF structures in both beams, and found to be $7500 \pm 3000 \mathrm{~m} \mathrm{~s}^{-1}$. The phase speed of Provan et al. (1998) is several times larger than the initial phase speed of $1850 \mathrm{~m} \mathrm{~s}^{-1}$ found using the full sixteen-beam scan of the overlapping CUTLASS radars in the present study. Provan et al. (1998) were also 
unable to distinguish any changes in the PIF speed as it evolved. Their errors were large, but they concluded that a there may have been a difference between the convection and phase velocities. The results were not definitive and they suggested further studies of the type presented here. Poleward-moving auroral forms, which were demonstrated to be co-located with radar PIFs (Yeoman et al., 1997), have been found to move eastward at a velocity of $1500 \mathrm{~m} \mathrm{~s}^{-1}$, assuming an emission altitude of $300 \mathrm{~km}$ (Sandholt et al., 1992). This value agrees very well with the phase speed in the first stage of the PIF evolution presented in the current study.

Chisham et al. (2000), who studied the convection response to reconnection in the throat of the dayside ionospheric convection pattern, found no change in the convection velocity within the PIF, as was found in the present study. Chisham et al. (2000) interpreted the lineof-sight velocity enhancements as simply a rotation of the convection pattern in the throat in response to the IMF $B_{y}$ tension force. The velocities that they examined were located in the region of the initial PIF response and they were unable to follow the PIF as it moved away from the noon-sector throat region of the dayside auroral zone. Chisham et al. (2000) were therefore not able to directly compare the motion of the PIF signature to the convection velocity. In general, the phase and convection velocities determined in the present study appear to be smaller than previous studies, as befits a magnetospherically quieter interval.

The size of the PIF was $2.4 \times 10^{5} \mathrm{~km}^{2}$ (approximately a circular patch of radius $275 \mathrm{~km}$ ) during the reconnection phase, when it covered $4 \mathrm{~h}$ of local time. Provan et al. (1998) estimated the size of the PIF to be between 1000 and $2800 \mathrm{~km}$ longitudinally and $250 \mathrm{~km}$ along the two radar beams. Their estimate along the beam agrees very well with the results presented here, but their extent in MLT was much larger. The study of ISEE 2, EISCAT, photometer and all-sky camera data by Elphic et al. (1990) found a more similar spatial extent of 400 to $1000 \mathrm{~km}$ in the east-west direction, and 100 to $200 \mathrm{~km}$ in the north-south direction.

Based on spacecraft measurements in the vicinity of the reconnection site at the magnetopause, Russell and Elphic (1978) suggested that FTEs involve only a short segment of the magnetopause, of the order $1 R_{E}$. They suggested that the newly opened flux is of the form of a flux rope of $1 R_{E}$ in diameter. Lockwood and Hapgood (1998) later demonstrated that the "2D reconnection" models of Saunders (1983) and Southwood et al. (1988), in which reconnection could occur along a length of the magnetopause possibly several $R_{E}$ long, were in better accordance with observation. In the present study, we have found that the PIF maps out to an area in the dipole ecliptic plane of approximately $0.5 R_{E}$ radially by $4 R_{E}$ in azimuth. During the reconnection phase of the PIF motion, the PIF traverses $4 \mathrm{~h}$ of MLT; as the reconnection region propagates anti-sunward along the magnetopause it "peels" magnetic flux from the magnetopause, as suggested by Milan et al. (2000).

Both the analysis of the ionospheric convection velocity relative to the motion of the equatorward spectral width boundary, a proxy for the ionospheric footprint of the magnetospheric reconnection X-line, and the map potential model showed that the reconnection increased the cross-polar cap potential difference by several tens of kilovolts. This exceeds the upper limit on the reconnection voltage of $14.5 \mathrm{kV}$ of Newell and Sibeck (1993) in which they estimated the size of the reconnection region in the ionosphere as $50 \times 500 \mathrm{~km}$. The present study shows that while the PIF is not much larger than this, reconnection continues for some $15 \mathrm{~min}$ whilst covering $4 \mathrm{~h}$ of MLT. Despite the indications that the interval presented here is a rather moderate one, the voltage added to the polar cap exceeds the upper estimate of Newell and Sibeck (1993). The results presented here are well within $160 \mathrm{kV}$ deduced by Milan et al. (2000) under very disturbed conditions, and well within the upper limit on the FTE contribution to the reconnection voltage of $200 \mathrm{kV}$ suggested by Lockwood et al. (1995).

\section{Summary and conclusions}

We have presented an interval of CUTLASS HF radar data in which two-dimensional ionospheric convection velocities are measured within the footprint of a magnetospheric flux transfer event. The preceding several hours of northward IMF and the resulting quiet magnetospheric conditions have allowed us to witness the isolated response of the ionosphere to a sharp southward turning of the IMF. Previous studies of PIFs have been limited by single radar measurements, and have had to infer convection velocities from uni-directional measurements of the plasma flow (e.g. Provan et al., 1998). The bistatic measurements of ionospheric convection during the lifetime of the first PIF in this interval allow a heretofore unavailable opportunity to compare the ionospheric convection velocity to the phase motion of the PIF as it travels deep into the polar cap.

The initial response in the ionosphere to the southward turning of the IMF occurs very close to magnetic local noon. This result was unexpected since the $B_{y}$ component, which is comparable in magnitude to $B_{z}$, statistically shifts the reconnection footprint into the morning sector. The first PIF traverses the radar field of view in half an hour, covering $6 \mathrm{~h}$ in local time in the expected direction as determined by $B_{y}$. The PIF appeared to follow the shortest possible path through the ionosphere, as evidenced by its strong agreement with the geodesic curve that was fit to the PIF trajectory.

The vector velocities measured within the PIF by the CUTLASS radar pair allowed a comparison of the phase motion of the PIF and the plasma convection velocity within it. The motion of the PIF was comprised of two main stages. During the first stage, the phase speed was fast and rapidly varying, with a mean speed of nearly twice the convection speed. During the second stage the phase velocity of the PIF slowed down to the convection velocity and became much more stable. The direction of the PIF phase velocity agreed within error with the direction of the ionospheric convection velocity. The velocity difference during the first stage has been 
interpreted as being due to active reconnection continuing on the magnetopause as the reconnection region moves azimuthally. The size of the PIF during the reconnection phase maps out to the magnetopause to an azimuthal extent of approximately $4 R_{E}$. This region of reconnection moves azimuthally through $4 \mathrm{~h}$ in MLT, peeling off flux from the magnetopause.

Once reconnection ceased, the PIF moved at the convection speed as the reconnected flux tubes convected antisunward with the solar wind. The magnetic field line tracing, and the line-of-sight power spectra and spectral widths support the interpretation of an interval of active reconnection followed by convection of the flux tubes into the plasma mantle as deduced from the velocity analysis. The strong backscattered power drops at approximately 11:15 UT, about the time when the velocity analysis showed that reconnection had ceased. The reduction in power may be due to a loss of source flux, which excites F-region irregularities associated with cusp precipitation. The spectral widths measured by both CUTLASS radars tend to decrease within the PIF signature as it moves anti-sunward. The narrowing of the spectra implies a reduction in the turbulence measured within the PIF as it evolves.

The appearance of the second PIF before the termination of the reconnection stage of the first PIF implies that during this interval reconnection was continuous, but occurring at different locations on the magnetopause. As one episode of flux transfer peeled flux from the magnetopause, another episode began, peeling off the newly exposed geomagnetic flux.

Using the spectral width boundary as a proxy for the ionospheric footprint of the reconnection X-line, we estimated the contribution of dayside reconnection to the cross-polar cap potential difference to be $57 \mathrm{kV}$. This agreed well with the modelled values obtained from the map potential model of Ruohoniemi and Baker (1998) of $60-70 \mathrm{kV}$.

From the ionospheric velocities, the solar wind conditions, and the geomagnetic activity measured, it appears that this was an interval of moderate pulsed reconnection. The affects on the magnetosphere, however, were considerable. Reconnection occurred over $4 \mathrm{~h}$ in MLT, and a significant amount of flux was added to the polar cap during the entire interval, resulting in a cross-polar cap potential difference of several tens of kilovolts.

Acknowledgements. CUTLASS is supported by the Particle Physics and Astronomy Research Council (PPARC grant PPA/R/R/ 1997/00256), UK, the Swedish Institute for Space Physics, Uppsala, and the Finnish Meteorological Institute, Helsinki. KAM would like to thank S. E. Milan and A. S. Rodger for many helpful discussions. KAM gratefully acknowledges graduate research funding from the Association of Commonwealth Universities of the British Council. The authors would like to thank the principal investigators R. P. Lepping and K. Ogilvie for the use of key parameter data from the WIND MFI and SWE instruments, respectively. The CANOPUS instrument array was constructed and is maintained and operated by the Canadian Space Agency for the Canadian scientific community.

Topical Editor G. Chanteur thanks J. Moen and W. Denig for their help in evaluating this paper.

\section{References}

André, R., M. Pinnock, and A. S. Rodger, On the SuperDARN autocorrelation function observed in the ionospheric cusp, Geophys. Res. Lett., 26, 3353-3356, 1999.

Baker, K. B., J. R. Dudeney, R. A. Greenwald, M. Pinnock, P. T. Newell, A. S. Rodger, N. Mattin, and C.-I. Meng, HF radar signatures of the cusp and low-latitude boundary layer, J. Geophys. Res., 100, 7671-7695, 1995.

Chisham, G., M. Pinnock, A. S. Rodger, and J.-P. Villain, Hightime resolution conjugate SuperDARN radar observations of the dayside convection response to changes in IMF $B_{y}$, Ann. Geophysicae, 18, 191-201, 2000.

Cowley, S. W. H., J. P. Morelli, and M. Lockwood, Dependence of convective flows and particle precipitation in the high-latitude dayside ionosphere on the $\mathrm{X}$ and $\mathrm{Y}$ components of the interplanetary magnetic field, J. Geophys. Res., 96, 5557-5564, 1991.

Elphic, R. C., M. Lockwood, S. W. H. Cowley, and P. E. Sandholt, Flux transfer events at the magnetopause and in the ionosphere, Geophys. Res. Lett., 17, 2241-2244, 1990.

Fasel, G. J., Dayside poleward moving auroral forms: a statistical study, J. Geophys. Res., 100, 11 891-11 905, 1995.

Frank, L. A., J. B. Sigwarth, J. D. Craven, J. P. Cravens, J. S. Dolan, M. R. Dvorsky, P. K. Hardebeck, J. D. Harvey, and D. W. Muller, The Visible Imaging System (VIS) for the Polar Spacecraft, Space Sci. Rev., 71, 297-328, 1995.

Goertz, C. K., E. Nielsen, A. Korth, K.-H. Glaßmeier, C. Haldoupis, P. Hoeg, and D. Hayward, Observations of a possible ground signature of flux transfer events, J. Geophys. Res., 90, 40694078, 1985.

Greenwald, R. A., W. Weiss, E. Nielsen, and N. R. Thomson, STARE: a new radar auroral backscatter experiment in northern Scandinavia, Radio Sci., 13, 1021-1039, 1978.

Greenwald, R. A., K. B. Baker, J. R. Dudeney, M. Pinnock, T. B. Jones, E. C. Thomas, J.-P. Villain, J.-C. Cerisier, C. Senior, C. Hanuise, R. D. Hunsucker, G. Sofko, J. Koehler, E. Nielsen, R. Pellinen, A. D. M. Walker, N. Sato, and H. Yamagishi, DARN/ SuperDARN: a global view of the dynamics of high-latitude convection, Space Sci. Rev., 71, 761-796, 1995.

Haerendel, G., G. Paschmann, N. Sckopke, H. Rosenbauer, and P. C. Hedgecock, The frontside boundary layer of the magnetopause and the problem of reconnection, J. Geophys. Res., 83, 3195, 1978.

Khan, H., and S. W. H. Cowley, Observations of the response time of high-latitude ionospheric convection to variations in the interplanetary magnetic field using EISCAT and IMP-8 data, Ann. Geophysicae, 17, 1306-1335, 1999.

Kuo, H., C. T. Russell, and G. Lee, Statistical studies of flux transfer events, J. Geophys. Res., 100, 3513-3519, 1995.

Lepping, R. P., M. H. Acuña, L. F. Burlaga, W. M. Farrell, J. A. Slavin, K. H. Schatten, F. Mariani, N. F. Ness, F. M. Neubauer, Y. C. Whang, J. B. Byrnes, R. S. Kennon, P. V. Panetta, J. Scheifele, and E. M. Worley, The WIND magnetic field investigation, Space Sci. Rev., 71, 207-229, 1995.

Lockwood, M., Ionospheric signatures of pulsed magnetopause reconnection, in Physical signatures of magnetopause boundary layer processes, NATO ASI Ser. C, vol 425, Eds. J. A. Holtet and A. Egeland, 229-243, Kluwer, Dordrecht, 1994.

Lockwood, M., and S. W. H. Cowley, Ionospheric convection and the substorm cycle, ICS-1 Proceedings, ESA SP-335, 99-109, 1992.

Lockwood, M., and M. N. Wild, On the quasi-periodic nature of magnetopause flux transfer events, J. Geophys. Res., 98, 5935$5940,1993$.

Lockwood, M., and M. A. Hapgood, On the cause of a magnetospheric flux transfer event, J. Geophys. Res., 103, 26 453-26 478, 1998.

Lockwood, M., J. Moen, S. W. H. Cowley, A. D. Farmer, U. P. Løvhaug, H. Lühr, and V. N. Davda, Variability of dayside 
convection and motions of the cusp/cleft aurora, Geophys. Res. Lett., 20, 1011-1014, 1993.

Lockwood, M., S. W. H. Cowley, J. Moen, P. E. Sandholt, and C. J. Owen, The contribution of flux transfer events to convection, Geophys. Res. Lett., 22, 1185-1188, 1995.

McWilliams, K. A., T. K. Yeoman, and G. Provan, A statistical survey of dayside pulsed ionospheric flows as seen by the CUTLASS Finland HF radar, Ann. Geophysicae, 18, 445-453, 2000.

Milan, S. E., T. K. Yeoman, M. Lester, E. C. Thomas, and T. B. Jones, Initial backscatter occurrence statistics from the CUTLASS HF radars, Ann. Geophysicae, 15, 703, 1997.

Milan, S. E., T. K. Yeoman, and M. Lester, The dayside auroral zone as a hard target for coherent HF radars, Geophys. Res. Lett., 25, 3717-3720, 1998 .

Milan, S. E., M. Lester, S. W. H. Cowley, J. Moen, P. E. Sandholt, and C. J. Owen, Meridian-scanning photometer, coherent HF radar, and magnetometer observations of the cusp: a case study, Ann. Geophysicae, 17, 159-172, 1999.

Milan, S. E., M. Lester, S. W. H. Cowley, and M. Brittnacher, Convection and auroral response to a southward turning of the IMF: Polar UVI, CUTLASS and IMAGE signatures of transient magnetic flux transfer at the magnetopause, J. Geophys. Res., 105, 15 741-15 756, 2000.

Moen, J., P. E. Sandholt, M. Lockwood, W. F. Denig, U. P. Løvhaug, B. Lybekk, A. Egeland, D. Opsvik, and E. FriisChristensen, Events of enhanced convection and related dayside auroral activity, J. Geophys. Res., 100, 23 917-23 934, 1995.

Neudegg, D. A., T. K. Yeoman, S. W. H. Cowley, G. Provan, G. Haerendel, W. Baumjohann, U. Auster, K.-H. Fornacon, E. Georgescu, and C. J. Owen, A flux transfer event observed at the magnetopause by the Equator-S spacecraft and in the ionosphere by the CUTLASS HF radar, Ann. Geophysicae, 17, 707-711, 1999.

Newell, P. T., and D. G. Sibeck, Upper limits on the contribution of flux transfer events to ionospheric convection, Geophys. Res. Lett., 20, 2829-2832, 1993.

Ogilvie, K. W., D. J. Chornay, R. J. Fritzenreiter, F. Hunsucker, J. Keller, J. Lobell, G. Miller, J. D. Scudder, E. C. Sittler, Jr., R. B. Torbert, D. Bodet, G. Needell, A. J. Lazarus, J. T. Steinberg, J. H. Tappan, A. Mavretic, and E. Gergin, SWE, a comprehensive plasma instrument for the WIND spacecraft, Space Sci. Rev., 71, 55-77, 1995.

Pinnock, M., A. S. Rodger, J. R. Dudeney, R. A. Greenwald, K. B. Baker, and J. M. Ruohoniemi, An ionospheric signature of possible enhanced field merging on the dayside magnetopause, J. Atmos. Terr. Phys., 53, 201-212, 1991.

Pinnock, M., A. S. Rodger, J. R. Dudeney, K. B. Baker, R. A. Greenwald, and M. Greenspan, Observations of an enhanced convection channel in the cusp ionosphere, J. Geophys. Res., 98, 3767-3776, 1993.
Pinnock, M., A. S. Rodger, J. R. Dudeney, F. Rich, and K. B. Baker, High spatial and temporal resolution observations of the ionospheric cusp, Ann. Geophysicae, 13, 919-925, 1995.

Provan, G., and T. K. Yeoman, Statistical observations of the MLT, latitude and size of the ionospheric signature of flux transfer events with the CUTLASS Finland radar, Ann. Geophysicae, 17, 855, 1999.

Provan, G., T. K. Yeoman, and S. E. Milan, CUTLASS Finland radar observations of the ionospheric signatures of flux transfer events and the resulting plasma flows, Ann. Geophysicae, 16, 1411-1422, 1998.

Rodger, A. S., M. Pinnock, J. R. Dudeney, K. B. Baker, and R. A. Greenwald, A new mechanism for polar patch formation, J. Geophys. Res., 99, 6425-6436, 1994.

Rostoker, G., J. C. Samson, F. Creutzberg, T. J. Hughes, D. R. McDiarmid, A. G. McNamara, A. Vallance Jones, D. D. Wallis, and L. L. Cogger, CANOPUS - a ground-based instrument array for remote sensing the high latitude ionosphere during the ISTP/GGS program, Space Sci. Rev., 71, 743-760, 1995.

Ruohoniemi, J. M., and K. B. Baker, Large-scale imaging of highlatitude convection with Super Dual Auroral Radar Network HF radar observations, J. Geophys. Res., 103, 20 797-20 811, 1998.

Russell, C. T., and R. C. Elphic, Initial ISEE magnetometer results: magnetopause observations, Space Sci. Rev., 22, 681-715, 1978.

Russell, C. T., and R. C. Elphic, ISEE observations of flux transfer events at the dayside magnetopause, Geophys. Res. Lett., 6, 3336, 1979.

Sandholt, P. E., J. Moen, and D. Opsvik, Periodic auroral events at the midday polar cap boundary: implications for solar windmagnetosphere coupling, Geophys. Res. Lett., 19, 1223-1226, 1992.

Saunders, M., Recent ISEE observations of the magnetopause and low-latitude boundary layer: a review, J. Geophys., 52, 190-198, 1983.

Southwood, D. J., C. J. Farrugia, and M. A. Saunders, What are flux transfer events?, Planet. Space Sci., 36, 503-508, 1988.

Torr, M. R., D. G. Torr, M. Zukic, R. B. Johnson, J. Ajello, P. Banks, K. Clark, K. Cole, C. Keffer, G. Parks, B. Tsurutani, and J. Spann, A far ultraviolet imager for the international solarterrestrial physics mission, Space Sci. Rev., 71, 329-383, 1995.

Tsyganenko, N. A., A magnetospheric magnetic field model with a warped tail current sheet, Planet. Space Sci., 37, 5-20, 1989.

Weber, E. J., J. Buchau, J. G. Moore, J. R. Sharber, R. C. Livingston, J. D. Winningham, and B. W. Reinisch, $F$ layer ionization patches in the polar cap, J. Geophys. Res., 89, 16831694, 1984.

Yeoman, T. K., M. Lester, S. W. H. Cowley, S. E. Milan, J. Moen, and P. E. Sandholt, Simultaneous observations of the cusp in optical, DMSP and HF radar data, Geophys. Res. Lett., 24:17, 2251-2254, 1997. 